\title{
Levantamento etnobotânico de plantas medicinais nos quintais do Bairro Novo Horizonte, Ituiutaba, MG
}

LIPORACCI, H.S.N'; SIMÃO, D.G. ${ }^{2 *}$

${ }^{1}$ Universidade Federal de Uberlândia, Faculdade de Ciências Integradas do Pontal, Av. José João Dib, 2545 Ituiutaba - MG - CEP 38302-000. ²Universidade Federal de Uberlândia, Instituto de Biologia, Caixa Postal 593

- Uberlândia - MG - CEP 38400-902 *dgsimao@inbio.ufu.br

RESUMO. Apesar da maioria dos estudos etnobotânicos serem focados em populações tradicionais, as populações de áreas urbanas também vêm sendo investigadas. O presente trabalho realizou um levantamento etnobotânico de plantas medicinais nos quintais de um bairro urbano, próximo à zona rural, no município de Ituiutaba, MG, visando resgatar e identificar o conhecimento local a respeito das plantas medicinais. Para isso, 40 residências foram visitadas e os dados coletados por meio de entrevistas semi-estruturadas realizadas com os moradores. Foram encontradas 72 espécies de plantas medicinais, distribuídas em 33 famílias botânicas, destacando-se Asteraceae e Lamiaceae pelo número de espécies. As cinco espécies mais citadas pelos moradores foram: Mentha sp., Cymbopogon citratus, Sedum dendroideum, Plectranthus barbatus, e Rosmarinus officinalis. O hábito herbáceo foi predominante, e a parte da planta mais usada foi a folha, enquanto a decocção foi o modo de preparo mais frequente. Por mais que existam particularidades entre os diversos costumes e culturas das comunidades locais no Brasil, foi observada similaridade entre os resultados encontrados neste trabalho com outros levantamentos realizados, reforçando a importância da preservação e divulgação do conhecimento popular.

Palavras chave: Asteraceae, conhecimento tradicional, etnobotânica, quintais.

ABSTRACT: Ethnobotanical survey of medicinal plants from home gardens of Bairro Novo Horizonte, Ituiutaba, MG. Much of the ethnobotanical research involves traditional populations, but urban and small urban centers with rural origins have been currently studied, so an ethnobotanical survey of medicinal plants was performed in the home gardens of Bairro Novo Horizonte, Ituiutaba, MG. Therefore, 40 households were visited and data were collected through semi-structured interviews. We found 72 species of medicinal plants distributed into 33 families, especially Asteraceae and Lamiaceae, by the number of species. The five species that were most frequently mentioned by residents were: Mentha sp. 2, Cymbopogon citratus, Sedum dendroideum, Plectranthus barbatus, and Rosmarinus officinalis. The herbaceous habit was predominant, the leaves were the most used part of the plant, and decoction was the dominant mode of use. Even though there are peculiarities across the various customs and cultures of local communities in Brazil, we are able to see a similarity amongst the results found here in relation to other researches, reinforcing the importance of preserving and disseminating the popular knowledge.

Keywords: Asteraceae, popular knowledge, ethnobotany, Mentha

\section{INTRODUÇÃO}

O homem desde a antiguidade sempre esteve ligado e dependente do universo vegetal e por meio de vivências e experiências aprendeu a retirar dele muito mais do que seu próprio sustento, utilizando-o também para finalidades medicinais, empíricas e simbólicas (Albuquerque, 2005; Lorenzi \& Matos, 2008).
No Brasil, sob influência das interações culturais entre índios, negros e portugueses, essa relação homem-natureza permitiu a disseminação da sabedoria herdada em relação ao uso e cultivo de diversas espécies vegetais (Almassy et al., 2005).

Conhecer o modo como estas espécies são utilizadas pode ser de grande valia para o homem,

Recebido para publicação em 16/12/2011

Aceito para publicação em 14/02/2013

Rev. Bras. PI. Med., Campinas, v.15, n.4, p.529-540, 2013. 
já que muitas comunidades, por manterem um contato duradouro e recíproco com os vegetais, desenvolveram um sistema de manejo próprio (Albuquerque \& Andrade, 2002). É por meio dessa relação homem-planta que a etnobotânica permite a descoberta de espécies que podem ser aproveitadas para a fabricação de medicamentos, alimentos, artesanato, dentre outros (Ming, 2001).

As pesquisas etnobotânicas, como observado por Pilla et al. (2006), estão ampliando a sua abordagem de populações tradicionais, como as indígenas (Di Stasi \& Hiruma-Lima, 2002; Bueno et al., 2005), caiçaras, ribeirinhas (Souza, 2007; Pasa \& Ávila, 2010; Miranda et al., 2011) e quilombolas (Franco \& Barros, 2006), para as populações urbanas (Castellucci et al., 2000; Marodin \& Baptista, 2001; Negrelle et al., 2007), rurais (Pinto et al., 2006; Liporacci et al., 2010; Roque et al., 2010) e pequenos núcleos urbanos com origem rural (SilvaAlmeida \& Amorozo, 1998; Garlet \& Irgang, 2001; Silva \& Andrade, 2005). Ambientes como mercados e feiras-livres também vêm sendo estudados neste aspecto (Azevedo \& Silva, 2006; Ustulin et al., 2009).

Na região do Triângulo Mineiro, estudos etnobotânicos já foram realizados em Martinésia (Salgado \& Guido, 2008; Damasceno \& Barbosa, 2008; Borges, 2009) e Cruzeiro dos Peixotos (Milani et al., 2011), ambos distritos da cidade de Uberlândia e em Indianópolis, no perímetro urbano e rural (Calábria et al., 2008). Já para o Pontal do Triângulo Mineiro, não se tem registro de estudos

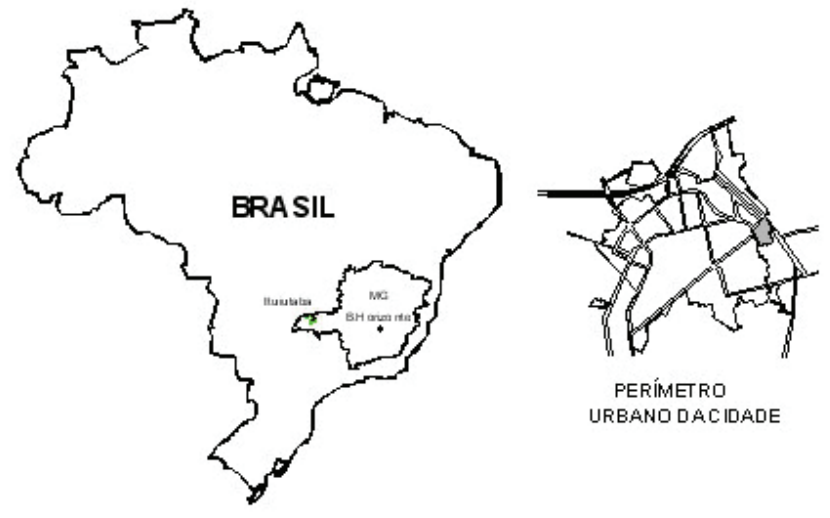

etnobotânicos. Diante deste contexto o presente estudo realizou um levantamento dos recursos vegetais utilizados para finalidades medicinais no bairro Novo Horizonte, município de Ituiutaba, MG, em função de sua proximidade com uma área de vegetação natural, procurando conhecer e resgatar o conhecimento tradicional dos moradores em relação ao uso de plantas medicinais.

\section{MATERIAL E MÉTODOS}

\section{Área de estudo}

O município de Ituiutaba localiza-se no centro-norte do Triângulo Mineiro, distante 761 $\mathrm{km}$ da capital Belo Horizonte. Possui uma área de $2.694 \mathrm{~km}^{2}$ tendo como vegetação típica o Cerrado (Prefeitura Municipal de Ituiutaba, 2011). O município possui atualmente 97.171 habitantes (47.862 homens e 49.309 mulheres), dentre esses, 93.125 residentes na área urbana e 4.046 na área rural, com uma densidade demográfica igual a $37,40 \mathrm{hab} /$ $\mathrm{km}^{2}$ (IBGE, 2010). A população economicamente ativa é de 49.862 habitantes (Prefeitura Municipal de Ituiutaba, 2011).

O bairro Novo Horizonte localiza-se na zona leste da cidade, tendo como bairros limítrofes, Setor Universitário, Camargo e Centro (Figura 1). O bairro faz limite também com uma área remanescente de Cerrado, atualmente em estágio de urbanização (observação pessoal). Segundo dados obtidos

BAIRRO NOVO HORIZONT E - ITUIUTABA - MG

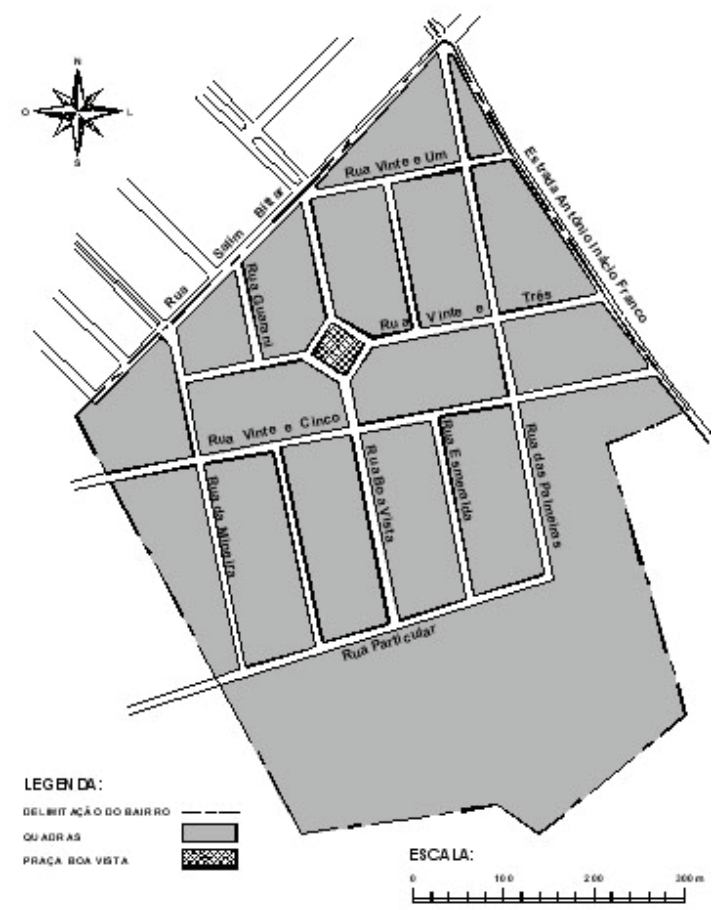

FIGURA 1. Mapa com a localização do Bairro Novo Horizonte, no município de Ituiutaba, MG. 
na Secretaria de Planejamento da Prefeitura de Ituiutaba, o bairro, fundado em 29 de dezembro de 1954, conta atualmente com uma área de $341.914 \mathrm{~m}^{2}$.

Desde o início de 2001, o bairro possui o Programa de Saúde da Família (PSF), onde estão cadastradas 147 famílias, constituídas por 273 homens e 245 mulheres. São 361 moradias existentes, todas possuindo tratamento de água filtrada e energia elétrica (T.W.A. Bueno, comunicação pessoal).

\section{Metodologia}

O levantamento etnobotânico sobre o uso das espécies medicinais nos quintais foi realizado por meio de entrevistas semi-estruturadas (Simão, 2003; Almeida et al., 2006), considerando o interesse e a disponibilidade dos moradores. Os que aceitaram participar do trabalho assinaram o Termo de Consentimento Livre e Esclarecido autorizando a realização da pesquisa. Para estas entrevistas, realizadas entre agosto de 2010 e janeiro de 2011, foram escolhidas aleatoriamente 40 residências no bairro, procurando-se abranger pelo menos uma casa por rua.

O número de casas visitadas equivale a $11,08 \%$ das existentes no bairro, sendo que a suficiência amostral, atingida quando um acréscimo de $10 \%$ no tamanho da amostra corresponde a $10 \%$ ou menos no número de espécies encontradas, foi verificada por meio da curva do coletor (Silva \& Loeck, 1999).

Para a coleta do material botânico utilizamos as seguintes metodologias: turnê-guiada com os moradores entrevistados (Albuquerque et al., 2010a), registro fotográfico, anotação em caderno de campo das características perdidas durante o processo de herborização, como cor da flor e do fruto, odores, como também a altura das plantas (Santos et al., 2010b). Para a herborização foram seguidos os procedimentos usuais de acordo com Fidalgo \& Bononi (1989). O número total de espécimes por quintal foi contabilizado objetivandose discutir a diferença na quantidade de plantas dentre as faixa-etárias dos entrevistados. O material botânico foi identificado por meio de literatura especializada (Lorenzi et al., 2006 ;Lorenzi \& Matos, 2008; Lorenzi \& Souza, 2008) e pela comparação com o acervo de plantas medicinais do Herbarium Uberlandensis (HUFU), da Universidade Federal de Uberlândia. Após a identificação, as exsicatas foram registradas e incorporadas ao acervo deste herbário. O sistema de classificação utilizado foi o APG III (2009) e os nomes científicos foram conferidos no site TROPICOSÒ, do Missouri Botanical Garden (TROPICOS 2012).

A terminologia utilizada pelos moradores para os modos de preparo dos medicamentos foi adaptada paras as categorias de Lorenzi \& Matos (2008) e ANVISA (2010). Já as doenças citadas pelos informantes foram classificadas de acordo com Almassy et al. (2005).

\section{RESULTADOS}

\section{Caracterização dos entrevistados}

Foram entrevistados 40 moradores, sendo 35 mulheres e cinco homens. Dentre as mulheres, a média de idade é de 61,7 anos, com uma variação entre 27 e 88 anos; entre os homens a média é de 63,4 anos, com uma variação entre 32 e 79 anos. A prevalência da idade dos entrevistados foi de 50 a 60 anos (Tabela 1). Do total de mulheres, $80 \%$ são donas de casa e $40 \%$ dos homens estão aposentados (Tabela 2). Em relação à escolaridade, prevaleceram os informantes com estudo até o ensino fundamental (65\%) (Tabela 3).

TABELA 1. Número dos entrevistados de diferentes faixas etárias em levantamento etnobotânico realizado no Bairro Novo Horizonte, Ituiutaba, MG.

\begin{tabular}{lccc}
\hline Faixa etária & \multicolumn{3}{c}{ Gênero (\%) } \\
\cline { 2 - 3 } TOTAL & Masculino & Feminino & \\
\hline $20-29$ anos & 0 & 7,5 & 7,5 \\
$30-39$ anos & 2,5 & 2,5 & 5 \\
$40-49$ anos & 0 & 10 & 10 \\
$50-59$ anos & 2,5 & 27,5 & 30 \\
$60-69$ anos & 0 & 25 & 25 \\
$70-79$ anos & 7,5 & 7,5 & 15 \\
$80-89$ anos & 0 & 7,5 & 7,5 \\
\hline TOTAL & $\mathbf{1 2 , 5}$ & $\mathbf{8 7 , 5}$ & $\mathbf{1 0 0}$ \\
\hline
\end{tabular}

TABELA 2. Atividade profissional dos homens e mulheres entrevistados no levantamento etnobotânico realizado no Bairro Novo Horizonte, Ituiutaba, MG.

\begin{tabular}{lcc}
\hline Atividade & \multicolumn{2}{c}{ Gênero (\%) } \\
\cline { 2 - 3 } Profissional & Masculino & Feminino \\
\hline Aposentado & 40 & 5,7 \\
Trabalhador Rural & 20 & - \\
Operador & 20 & - \\
Lavrador & 20 & - \\
Doméstica & - & 80 \\
Cozinheira & - & 2,8 \\
Estudante & - & 2,8 \\
Costureira & - & 8,6 \\
\hline Total & $\mathbf{1 0 0}$ & $\mathbf{1 0 0}$ \\
\hline
\end{tabular}


TABELA 3. Escolaridade dos entrevistados no levantamento etnobotânico realizado no Bairro Novo Horizonte, Ituiutaba, MG.

\begin{tabular}{lc}
\hline Escolaridade & Entrevistados (\%) \\
\hline Sem estudos & 25 \\
Ensino Fundamental (1 ${ }^{\text {a }}$ a $7^{\text {a }}$ série) & 65 \\
Ensino Médio completo & 7,5 \\
Curso superior completo & 2,5 \\
\hline Total & $\mathbf{1 0 0}$ \\
\hline
\end{tabular}

\section{Dados etnobotânicos}

$\mathrm{Na}$ área amostrada, para uma equação $\mathrm{y}=$ $18,472 \ln (x)+4,7796$ da curva logarítmica ajustada (Figura 2), verificou-se que um aumento de $10 \%$ no número de coletas (de 40 para aproximadamente 44), refletiu-se em aumento no número cumulativo de espécies da ordem de $2,41 \%$, indicando que a quantidade de residências amostradas neste local foi suficiente (Silva \& Loeck, 1999).

Pelas entrevistas, foram obtidas 292 citações relativas a 72 espécies pertencentes a 33 famílias (Tabela 4). Dentre as famílias com maior número de espécies se encontram Asteraceae e Lamiaceae (Figura 3). Em relação às espécies citadas, o hábito herbáceo foi o mais encontrado $(55,77 \%)$ e o modo de preparo prevalecente foi o chá, obtido por decocção, com 34,2\% (Figuras 4-5).

As cinco espécies mais encontradas e citadas foram: Mentha sp. 2 (18 citações), com 50\% de utilização contra doenças do Sistema Respiratório; Cymbopogon citratus (16), com 56,25\% de utilização contra doenças do Sistema Circulatório; Sedum dendroideum (15) e Plectranthus barbatus (14), ambos com $100 \%$ de utilização contra doenças do Sistema Digestivo; e Rosmarinus officinalis (14), com $64,3 \%$ de utilização contra doenças do Sistema Nervoso.

A parte da planta mais empregada foi a folha $(86,6 \%)$, seguida da raiz $(8,2 \%)$, flor $(3,4 \%)$, fruto $(1 \%)$, semente e casca do tronco $(0,8 \%)$.

O maior número de citações de doenças e sintomas foi para o grupo relacionado ao Sistema Digestivo (30\%): úlcera, gastrite, azia, males do estômago, diabete, problemas no fígado e verminoses. Em seguida, encontram-se aquelas relacionadas ao Sistema Respiratório $(26,4 \%)$, como gripe, bronquite, pneumonia, tosse, dor de garganta e resfriado. As doenças e sintomas que podem estar relacionados com o Sistema Nervoso, como dor de cabeça, labirintite, enxaqueca, depressão e nervosismo, obtiveram 13,7\%. Machucados, pancadas, arranhões e ferimentos representaram $9,2 \%$ das citações. Com $7,2 \%$ ficaram as doenças relacionadas ao Sistema Circulatório, como pressão alterada, males do coração, hemorróida, impurezas no sangue e anemia. Com uma porcentagem menor encontram-se aquelas que acometem - Sistema Urinário (males dos rins, bexiga e cistite), com 5,1\%, e o Sistema Reprodutor (cólica menstrual, impotência, corrimento, limpeza de útero, menopausa), com $3,8 \%$. Outras citações, como catarata, câncer, verruga, mau-olhado e picada de cobra ficaram com 4,6\% (Figura 6).

A maioria dos moradores prefere utilizar os remédios naturais, principalmente em relação às doenças mais comuns no dia-a-dia, como: gripe, resfriado, dor de cabeça, tosse, azia e dor no estômago. A busca por medicamentos industrializados ocorre só nos casos urgentes, nos quais as plantas já não atendem mais as

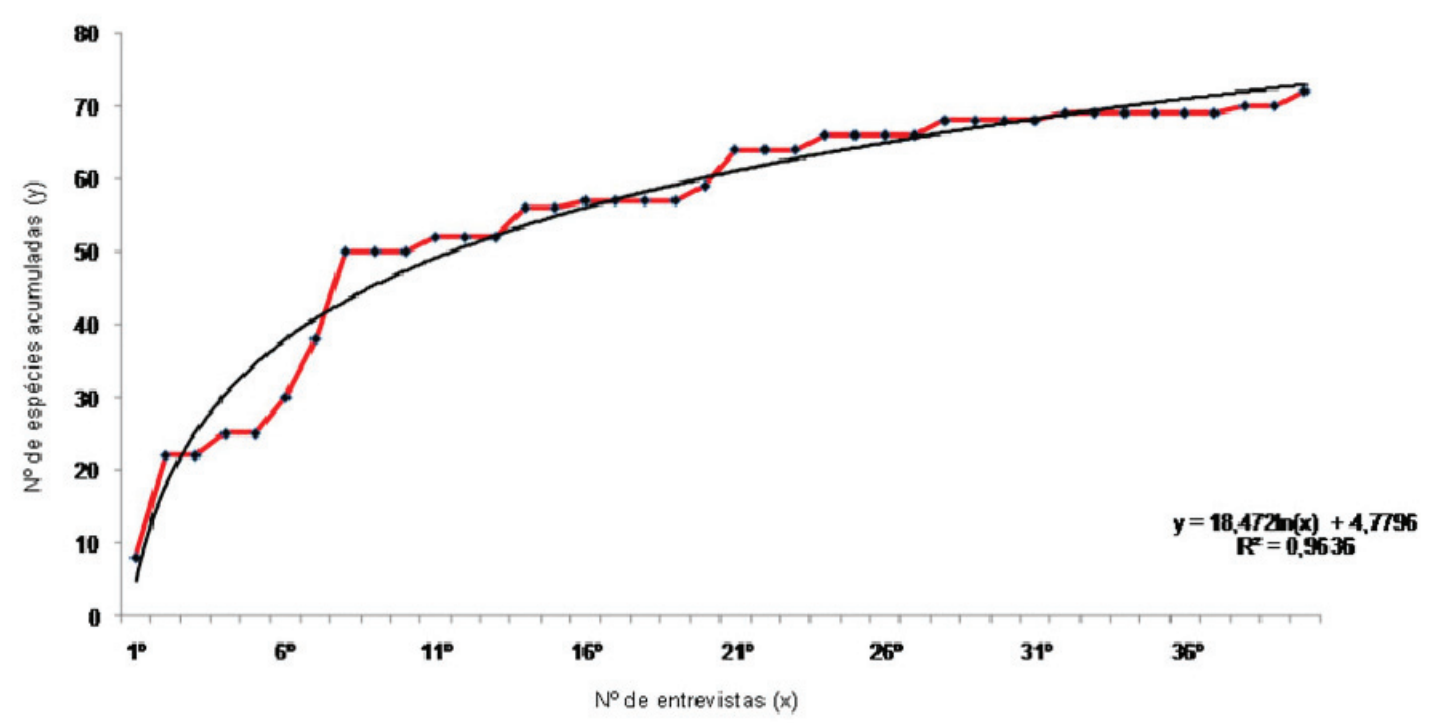

FIGURA 2. Curva do coletor (linha ajustada); curva do coletor seguindo a ordem de coleta dos dados (linha em vermelho). 
TABELA 4. Relação das espécies de plantas medicinais agrupadas por famílias. (HA = hábito: $H=$ herbáceo, $A=$ arbustivo, $S=$ subarbustivo, $A R=$ arbóreo, $T=$ trepadeira; $P U=$ parte usada: $F=$ folha, $F R=$ fruto, $F L=$ flor, $\mathrm{R}=$ raiz; $\mathrm{SE}=$ semente; $\mathrm{P}=$ planta inteira. $\mathrm{REG}=\mathrm{n}$-ode registro do herbário ou $\mathrm{n}$ ㅇ do coletor).

\begin{tabular}{|c|c|c|c|c|c|c|}
\hline TÁXONS & $\begin{array}{l}\text { NOME } \\
\text { POPULAR }\end{array}$ & $\begin{array}{l}\text { INDICAÇÂO } \\
\text { TERAPÊUTICA }\end{array}$ & $\begin{array}{l}\text { MODO DE PREPARO } \\
\text { OU DE USO }\end{array}$ & HA & PU & REG \\
\hline \multicolumn{7}{|l|}{ ACANTHACEAE } \\
\hline Justicia pectoralis Jacq. & Anador & Dores em geral & Decocção & $\mathrm{H}$ & $\mathrm{F}$ & HL22 \\
\hline \multicolumn{7}{|l|}{ ADOXACEAE } \\
\hline Sambucus australis Cham. \& Schltdl. & Sabugueiro & $\begin{array}{l}\text { Bronquite, gripe, sarampo e catapora } \\
\text { em criança }\end{array}$ & Infusão, xarope & A & $\mathrm{F}, \mathrm{FL}$ & 59397 \\
\hline \multicolumn{7}{|l|}{ AMARANTHACEAE } \\
\hline Alternanthera brasiliana (L.) Kuntze & Mercúrio & Cortes e machucados & Tintura & $\mathrm{S}$ & $\mathrm{FL}$ & HL140 \\
\hline Chenopodium ambrosioides $\mathrm{L}$. & $\begin{array}{l}\text { Erva-de-santa- } \\
\text { maria, mastruz }\end{array}$ & $\begin{array}{l}\text { Gripe, gastrite, machucados, úlcera, } \\
\text { vermífugo }\end{array}$ & $\begin{array}{l}\text { Compressa, decocção, } \\
\text { Infusão, xarope }\end{array}$ & $\mathrm{H}$ & $\mathrm{F}$ & 59400 \\
\hline \multicolumn{7}{|l|}{ ANACARDIACEAE } \\
\hline Anacardium occidentale $\mathrm{L}$. & Caju & Diarréia & Suco & AR & FR & 59386 \\
\hline Mangifera indica $\mathrm{L}$. & Manga rosinha & Gripe & Infusão & $A R$ & $\mathrm{~F}$ & HL 91 \\
\hline \multicolumn{7}{|l|}{ ANNONACEAE } \\
\hline Annona muricata L. & Graviola & Câncer, emagrecer, falta de ar & Infusão & AR & $\mathrm{F}$ & 59405 \\
\hline \multicolumn{7}{|l|}{ APIACEAE } \\
\hline Foeniculum vulgare Mill. & Funcho, erva doce & Calmante, gripe, vermífugo & Decocção, infusão & $\mathrm{H}$ & $\mathrm{F}$ & 59393 \\
\hline Petroselinum crispum (Mill.) Fuss & Salsa & $\begin{array}{l}\text { Inflamação no estômago, limpeza } \\
\text { no útero }\end{array}$ & Garrafada, ingestão & $\mathrm{H}$ & $\mathrm{F}$ & HL224 \\
\hline \multicolumn{7}{|l|}{ APOCYNACEAE } \\
\hline Catharanthus roseus (L.) G.Don & $\begin{array}{l}\text { Boa noite, maria- } \\
\text { sem-vergonha }\end{array}$ & Câncer & Infusão & S & $\mathrm{F}$ & 59387 \\
\hline Himatanthus drasticus (Mart.) Plumel & $\begin{array}{l}\text { Cola nota, tiborna } \\
\text { caseira }\end{array}$ & Câncer, estômago, gastrite, verruga & $\begin{array}{l}\text { Pingar o látex no local } \\
\text { ou na água e beber }\end{array}$ & AR & $\mathrm{F}$ & HL55 \\
\hline Plumeria rubra L. & Jasmim & Estancar o sangue & Pingar o látex no local & A & $\mathrm{F}$ & HL102 \\
\hline \multicolumn{7}{|l|}{ ARACEAE } \\
\hline Anthurium affine Schott & Salsa paredão & $\begin{array}{l}\text { Corrimento de mulher, depurativo do } \\
\text { sangue, dor muscular, infecção de } \\
\text { útero e ovário, infecções }\end{array}$ & $\begin{array}{l}\text { Decocção, garrafada, } \\
\text { tintura }\end{array}$ & $\mathrm{H}$ & $\mathrm{R}$ & HL162 \\
\hline Dieffenbachia picta Schott & $\begin{array}{l}\text { Comigo-ninguém- } \\
\text { pode }\end{array}$ & Mau olhado & Ter a planta em casa & $\mathrm{H}$ & $\mathrm{P}$ & HL119 \\
\hline $\begin{array}{l}\text { Philodendron bipinnatifidum Schott ex } \\
\text { Endl. }\end{array}$ & Cipó imbé & Contra dor & Banho & $\mathrm{H}$ & $\mathrm{F}$ & HL138 \\
\hline \multicolumn{7}{|l|}{ ASTERACEAE } \\
\hline Ageratum conyzoides $\mathrm{L}$. & Mentrasto & $\begin{array}{l}\text { Anti-inflamatório, cicatrizante, dor } \\
\text { de cabeça }\end{array}$ & Decocção & $\mathrm{H}$ & $\mathrm{F}$ & 59413 \\
\hline Artemisia absinthium $\mathrm{L}$. & Losna & $\begin{array}{l}\text { Dor de cabeça, estômago, } \\
\text { machucados }\end{array}$ & Banho, decocção, & S & $\mathrm{F}$ & 59395 \\
\hline Artemisia alba Turra & Alcanfor & $\begin{array}{l}\text { Doença no umbigo de criança, } \\
\text { machucados, rins }\end{array}$ & Banho, compressa & $\mathrm{H}$ & $\mathrm{F}$ & HL28 \\
\hline Baccharis trimera (Less.) DC. & Carqueja & Colesterol, diabete, estômago ruim & Decocção & S & $\mathrm{F}$ & HL48 \\
\hline Bidens pilosa $\mathrm{L}$. & Picão & Anemia de criança, hepatite & Banho, decocção & $\mathrm{H}$ & $\mathrm{F}$ & HL238 \\
\hline Mikania glomerata Spreng. & Guaco & $\begin{array}{l}\text { Bronquite, cicatrizante, febre, } \\
\text { garganta, gripe }\end{array}$ & Infusão, tintura, xarope & $\mathrm{T}$ & $\mathrm{F}$ & HL25 \\
\hline Solidago chilensis Meyen & Arnica & $\begin{array}{l}\text { Cortes, dores em geral, ferimentos, } \\
\text { infecção, machucados, pancada }\end{array}$ & Tintura & S & $\mathrm{F}$ & 59421 \\
\hline Tanacetum parthenium (L.) Sch. Bip. & Artimígio & $\begin{array}{l}\text { Cólica menstrual, derrame, labirinto, } \\
\text { limpeza de útero }\end{array}$ & Infusão & $\mathrm{H}$ & $\mathrm{F}$ & 59423 \\
\hline Vernonia condensata Baker & Caferana & $\begin{array}{l}\text { Emagrecer, má digestão, males do } \\
\text { estômago, ressaca }\end{array}$ & Decocção & A & $\mathrm{F}$ & 59414 \\
\hline \multicolumn{7}{|l|}{ BALSAMINACEAE } \\
\hline Impatiens walleriana Hook. f. & Bejinho & Cistite & Infusão & $\mathrm{H}$ & $\mathrm{F}$ & 59389 \\
\hline \multicolumn{7}{|l|}{ BORAGINACEAE } \\
\hline Symphytum officinale L. & Confrei & Dor no corpo, pancada & Infusão & $\mathrm{H}$ & $\mathrm{F}$ & HL196 \\
\hline \multicolumn{7}{|l|}{ BRASSICACEAE } \\
\hline Lepidium virginicum $\mathrm{L}$. & Agrião & Bronquite, gastrite, úlcera & Decocção, xarope & $\mathrm{H}$ & $\mathrm{F}$ & 59404 \\
\hline Tarenaya hassleriana (Chodat) H.H. Iltis & Mussambê & Bronquite & Infusão & $\mathrm{H}$ & $\mathrm{FL}$ & 59384 \\
\hline \multicolumn{7}{|l|}{ CARICACEAE } \\
\hline Carica papaya L. & Mamão & $\begin{array}{l}\text { Congestão, cortar vômito, limpar o } \\
\text { estômago, intoxicação }\end{array}$ & Decocção & $A$ & $\mathrm{~F}$ & HL168 \\
\hline
\end{tabular}

Rev. Bras. Pl. Med., Campinas, v.15, n.4, p.529-540, 2013. 
TABELA 4. Relação das espécies de plantas medicinais agrupadas por famílias. (HA = hábito: $H=$ herbáceo, $A=$ arbustivo, $S=$ subarbustivo, $A R=$ arbóreo, $T=$ trepadeira; $P U=$ parte usada: $F=$ folha, $F R=$ fruto, $F L=$ flor, $\mathrm{R}=$ raiz; $\mathrm{SE}=$ semente $; \mathrm{P}=$ planta inteira. $\mathrm{REG}=\mathrm{n}$-de registro do herbário ou $\mathrm{n}$ - do coletor).

\begin{tabular}{|c|c|c|c|c|c|c|}
\hline TÁXONS & $\begin{array}{l}\text { NOME } \\
\text { POPULAR }\end{array}$ & $\begin{array}{l}\text { INDICAÇÂO } \\
\text { TERAPÊUTICA }\end{array}$ & $\begin{array}{l}\text { MODO DE PREPARO } \\
\text { OU DE USO }\end{array}$ & HA & PU & REG \\
\hline \multicolumn{7}{|l|}{ CELASTRACEAE } \\
\hline Maytenus ilicifolia (Schrad.) Planch & Espinheira-santa & Úlcera & Decocção & A & $\mathrm{F}$ & 45973 \\
\hline \multicolumn{7}{|l|}{ COSTACEAE } \\
\hline Costus spicatus (Jacq.) Sw. & Cana-de-macaco & $\begin{array}{l}\text { Anti-inflamatório, pedra nos rins, } \\
\text { bexiga }\end{array}$ & Decocção & $\mathrm{H}$ & $\mathrm{F}, \mathrm{FL}$ & 41403 \\
\hline \multicolumn{7}{|l|}{ CRASSULACEAE } \\
\hline Sedum dendroideum Moc. \& Sessé ex DC. & $\begin{array}{l}\text { Balsaminho, } \\
\text { bálsamo }\end{array}$ & $\begin{array}{l}\text { Catarata, cicatrizante, cólica, dor } \\
\text { de ouvido, dor em geral, gastrite, } \\
\text { labirintite, machucados, males do } \\
\text { coração, olho ressecado, úlcera }\end{array}$ & $\begin{array}{l}\text { Banho, colírio, } \\
\text { decocção, ingestão, } \\
\text { pingar o sumo no } \\
\text { ouvido, }\end{array}$ & $\mathrm{H}$ & $\mathrm{F}$ & 57059 \\
\hline Bryophyllum pinnatum (Lam.) Oken & Folha-santa & Dor de cabeça & Compressa, infusão & $\mathrm{H}$ & $\mathrm{F}$ & 41443 \\
\hline \multicolumn{7}{|l|}{ CUCURBITACEAE } \\
\hline Momordica charantia L. & Erva-de-são-caetano & Coceira, pneumonia & Banho, infusão & $\mathrm{T}$ & $\mathrm{F}$ & 59382 \\
\hline EUPHORBIACEAE & Pinhão manso & & & & & \\
\hline Jatropha curcas L. & Pinhão roxo & Picada de cobra & Compressa & A & $\mathrm{F}$ & HL173 \\
\hline Jatropha gossypiifolia L. & Mercúrio & Hemorróida & Banho & $A$ & $\mathrm{~F}$ & 44435 \\
\hline Jatropha multifida L. & & Feridas & Pingar o látex no local & A & $\mathrm{F}$ & 59403 \\
\hline FABACEAE & Sene & & & & & \\
\hline Cassia angustifolia Vahl & & Dor no corpo & Decocção & A & $\mathrm{F}$ & 59409 \\
\hline LAMIACEAE & Poejo & & & & & \\
\hline Mentha pulegium $\mathrm{L}$. & Alevante & Brotoeja em crianças, gripe & Decocção, infusão & $\mathrm{H}$ & $\mathrm{F}$ & HL180 \\
\hline Mentha sp.1 & Hortelã & Bom para dormir, gripe de criança & Infusão & $\mathrm{H}$ & $\mathrm{F}$ & HL 60 \\
\hline Mentha sp.2 & Manjericão & $\begin{array}{l}\text { Anti-inflamatório, calmante, } \\
\text { cicatrizante, diabete, gastrite, gripe, } \\
\text { tosse, úlcera, vermífugo }\end{array}$ & $\begin{array}{l}\text { Decocção, infusão, } \\
\text { xarope }\end{array}$ & $\mathrm{H}$ & $\mathrm{F}$ & HL59 \\
\hline Ocimum basilicum L. & Alfavacão, alfavaca, & $\begin{array}{l}\text { Calmante, enxaqueca, febre, gripe, } \\
\text { problemas intestinais }\end{array}$ & Infusão, decocção & S & $\mathrm{F}$ & 59420 \\
\hline Ocimum sp. & $\begin{array}{l}\text { favaca, favaquinha, } \\
\text { loro } \\
\text { Hortelã-pimenta, }\end{array}$ & $\begin{array}{l}\text { Bronquite, calmante, gripe, peito } \\
\text { cheio }\end{array}$ & Decocção, infusão & $\mathrm{S}$ & $\mathrm{F}$ & 59388 \\
\hline Plectranthus amboinicus (Lour.) Spreng. & $\begin{array}{l}\text { hortelã-da-folha- } \\
\text { gorda,hortelã-da- } \\
\text { folha-larga } \\
\text { Boldo }\end{array}$ & $\begin{array}{l}\text { Bronquite, dor de cabeça, gripe, mal } \\
\text { estar, tosse }\end{array}$ & $\begin{array}{l}\text { Decocção, infusão, } \\
\text { xarope }\end{array}$ & $\mathrm{H}$ & $\mathrm{F}$ & 59399 \\
\hline $\begin{array}{l}\text { Plectranthus barbatus Andrews } \\
\text { Plectranthus ornatus Codd }\end{array}$ & $\begin{array}{l}\text { Melhoral, boldo } \\
\text { japonês, boldo } \\
\text { chileno } \\
\text { Alecrim }\end{array}$ & $\begin{array}{l}\text { Lombrigueiro, males do estômago } \\
\text { Dor no estômago, febre, gastrite, } \\
\text { males do estômago, ressaca }\end{array}$ & $\begin{array}{l}\text { Decocção, xarope } \\
\text { Infusão, maceração }\end{array}$ & $\mathrm{S}$ & $\mathrm{F}$ & 59401 \\
\hline Rosmarinus officinalis L. & & $\begin{array}{l}\text { Antidepressivo, bom para o coração, } \\
\text { calmante, diabete, doença no } \\
\text { umbigo de criança, dor de cabeça, } \\
\text { gripe, pressão alta }\end{array}$ & Decocção, infusão & $\mathrm{H}$ & $\mathrm{F}$ & HL277 \\
\hline LYTHRACEAE & Romã & & & & & \\
\hline Punica granatum $\mathrm{L}$. & & Infecção de garganta, infecções & Decocção, gargarejo & $\mathrm{S}$ & $\mathrm{F}$ & 59408 \\
\hline MORACEAE & Amora & & & & & \\
\hline Morus nigra L. & & $\begin{array}{l}\text { Estômago, pressão alta, regular a } \\
\text { menopausa }\end{array}$ & Infusão & A & $\mathrm{F}, \mathrm{FR}$ & 59417 \\
\hline PASSIFLORACEAE & Maracujá & & & & & \\
\hline Passiflora sp. & & Calmante & Suco & A & $\mathrm{F}, \mathrm{FR}$ & 59391 \\
\hline PHYLLANTHACEAE & Quebra-pedra & & & & & \\
\hline Phyllanthus niruri L. & & Bexiga, diurético, males dos rins & Decocção, infusão & $\mathrm{T}$ & FR & 59381 \\
\hline PHYTOLACCACEAE & Guiné & & & & & \\
\hline Petiveria alliacea L. & & $\begin{array}{l}\text { Cólica, dores, gripe, inveja, mau } \\
\text { olhado, olho gordo, tosse }\end{array}$ & $\begin{array}{l}\text { Banho, decocção, } \\
\text { possuir a planta, xarope }\end{array}$ & $\mathrm{H}$ & $\mathrm{F}$ & 59392 \\
\hline PLANTAGINACEAE & Transagem & & & & & \\
\hline Plantago major L. & & $\begin{array}{l}\text { Antibiótico, anti-inflamatório, gripe, } \\
\text { infecção de mulher, infecção nos } \\
\text { rins, machucados }\end{array}$ & $\begin{array}{l}\text { Banho, decocção, } \\
\text { infusão, ingestão }\end{array}$ & $\mathrm{H}$ & $\mathrm{P}, \mathrm{F}$ & 59406 \\
\hline
\end{tabular}


TABELA 4. Relação das espécies de plantas medicinais agrupadas por famílias. (HA = hábito: $H=$ herbáceo, $A=$ arbustivo, $S=$ subarbustivo, $A R=$ arbóreo, $T=$ trepadeira; $P U=$ parte usada: $F=$ folha, $F R=$ fruto, $F L=$ flor, $\mathrm{R}=$ raiz; $\mathrm{SE}=$ semente; $\mathrm{P}=$ planta inteira. $R E G=$ no-de registro do herbário ou no do coletor).

\begin{tabular}{|c|c|c|c|c|c|c|}
\hline TÁXONS & $\begin{array}{l}\text { NOME } \\
\text { POPULAR }\end{array}$ & $\begin{array}{l}\text { INDICAÇÂO } \\
\text { TERAPÊUTICA }\end{array}$ & $\begin{array}{l}\text { MODO DE PREPARO } \\
\text { OU DE USO }\end{array}$ & HA & PU & REG \\
\hline \multicolumn{7}{|l|}{ POACEAE } \\
\hline Cymbopogon citratus (DC.) Stapf & $\begin{array}{l}\text { Capim cidreira, } \\
\text { capim-santo, erva- } \\
\text { cidreira }\end{array}$ & $\begin{array}{l}\text { Antidepressivo, calmante, febre, } \\
\text { gripe, pressão alta }\end{array}$ & Decocção & $\mathrm{H}$ & $\mathrm{F}$ & 59047 \\
\hline Coix lacryma-jobi L. & Conta-de-lágrimas & Males dos rins e bexiga & Decocção & $\mathrm{H}$ & $F, R$ & 37418 \\
\hline \multicolumn{7}{|l|}{ POLYGONACEAE } \\
\hline Polygonum hydropiperoides Michx. & Erva-de-bicho & Hemorróida & Banho, decocção & $\mathrm{H}$ & $\mathrm{F}, \mathrm{SE}$ & 59424 \\
\hline \multicolumn{7}{|l|}{ PTERIDACEAE } \\
\hline Adiantum sp. & Avenca & Gripe, resfriado, tosse & Infusão & $\mathrm{H}$ & $\mathrm{F}$ & 59374 \\
\hline \multicolumn{7}{|l|}{ RUTACEAE } \\
\hline Ruta graveolens L. & Arruda & $\begin{array}{l}\text { Afasta os males e mau olhado, } \\
\text { controlador menstrual, dor de } \\
\text { cabeça, dor no estômago, fígado, } \\
\text { irritação nos olhos, recaída de } \\
\text { mulher }\end{array}$ & $\begin{array}{l}\text { Colírio, decocção, } \\
\text { infusão }\end{array}$ & $\mathrm{H}$ & $\mathrm{F}$ & HL 82 \\
\hline Citrus sp. & Limão china & Gripe & Infusão & $\mathrm{S}$ & $\mathrm{F}$ & 59396 \\
\hline \multicolumn{7}{|l|}{ VERBENACEAE } \\
\hline $\begin{array}{l}\text { Lippia alba (Mill.) N.E. Br. ex Britton \& P. } \\
\text { Wilson }\end{array}$ & Erva-cidreira, melissa & $\begin{array}{l}\text { Calmante, cólica, dor de barriga, } \\
\text { machucado, pressão alta }\end{array}$ & Infusão & A & $\mathrm{F}$ & HL86 \\
\hline Stachytarpheta cayennensis (Rich.) Vahl & Gervão & Bronquite, febre, gripe & $\begin{array}{l}\text { Infusão, decocção, } \\
\text { tintura }\end{array}$ & $\mathrm{S}$ & $\mathrm{F}$ & 59402 \\
\hline \multicolumn{7}{|l|}{ XANTHORRHOEACEAE } \\
\hline \multirow[t]{2}{*}{ Aloe sp. } & Babosa & $\begin{array}{l}\text { Afta, anti-inflamatório para ferida, } \\
\text { bom para o cabelo, câncer, caspa, }\end{array}$ & $\begin{array}{l}\text { Passar a mucilagem } \\
\text { no local }\end{array}$ & $\mathrm{S}$ & $\mathrm{F}$ & 59378 \\
\hline & & $\begin{array}{l}\text { coceira, ferimento, machucado, } \\
\text { queimadura }\end{array}$ & & $\mathrm{H}$ & $\mathrm{F}$ & HL101 \\
\hline \multicolumn{7}{|l|}{ ZINGIBERACEAE } \\
\hline Zingiber officinale Roscoe & Gengibre & $\begin{array}{l}\text { Gripe, dor de cabeça, dor de } \\
\text { estômago, tosse }\end{array}$ & Decocção, ingestão & $\mathrm{H}$ & $\mathrm{R}$ & 59427 \\
\hline Curcuma longa L. & Açafrão & Tosse & Decocção & $\mathrm{H}$ & $\mathrm{F}$ & HL288 \\
\hline \multicolumn{7}{|l|}{ INDETERMINADAS } \\
\hline Indet. 01 & Angélica & Dor de cabeça, recaída & Decocção & $\mathrm{H}$ & $\mathrm{R}$ & HL80 \\
\hline Indet. 02 & Ingerca & Limpeza de útero & Xarope & $\mathrm{H}$ & $\mathrm{F}$ & HL121 \\
\hline Indet. 03 & Alho de folha & Afrodisíaco & Infusão & $\mathrm{H}$ & $\mathrm{F}$ & HL74 \\
\hline Indet. 04 & Alfazema & Calmante, labirinto, pressão alta & Decocção & A & $\mathrm{F}$ & 59384 \\
\hline Indet. 05 & Melhoral & Febre & Infusão & $\mathrm{S}$ & $\mathrm{F}$ & HL194 \\
\hline Indet. 06 & Cipó-cabeça-de-nego & Fígado, impotência & Garrafada & $\mathrm{T}$ & $\mathrm{R}$ & HL57 \\
\hline Indet. 07 & Marcelinha & Cortar o vômito & Decocção & $\mathrm{H}$ & $\mathrm{F}$ & HL266 \\
\hline Indet. 08 & Melhoral & Gripe & Decocção & $\mathrm{H}$ & $\mathrm{F}$ & HL275 \\
\hline
\end{tabular}

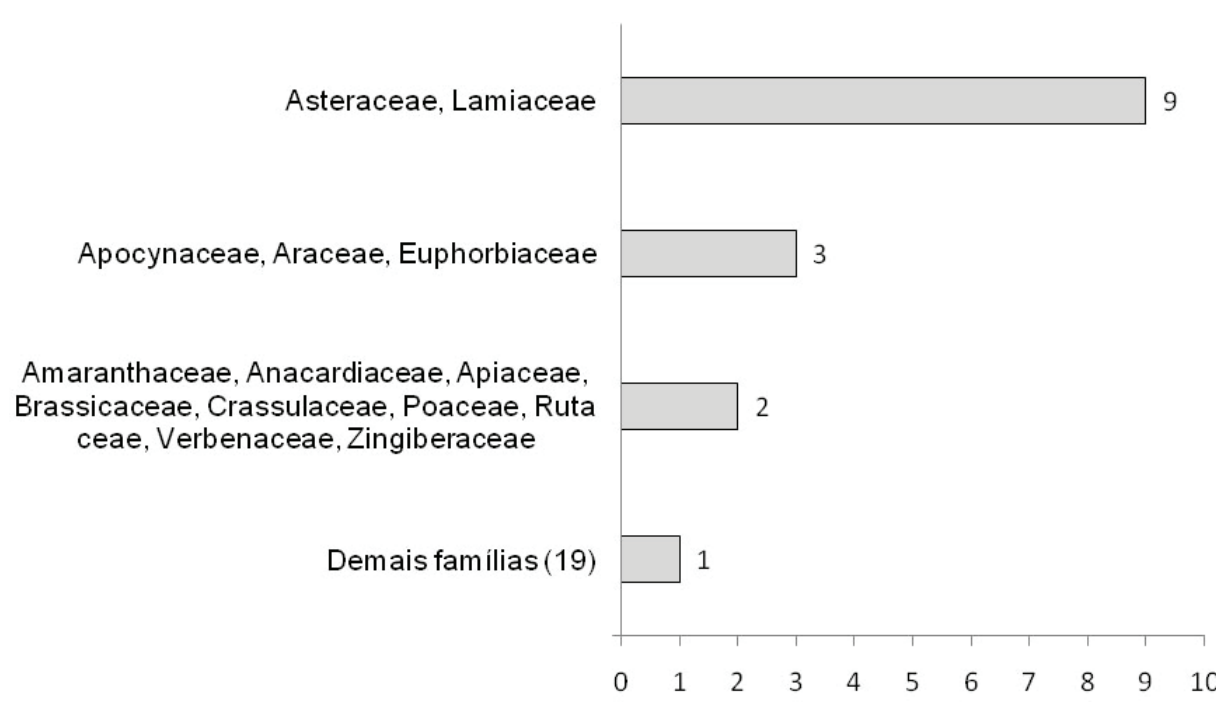

FIGURA 3. Número de espécies por família dentre as utilizadas como medicinais por moradores do bairro Novo Horizonte, Ituiutaba, MG.

Rev. Bras. PI. Med., Campinas, v.15, n.4, p.529-540, 2013. 


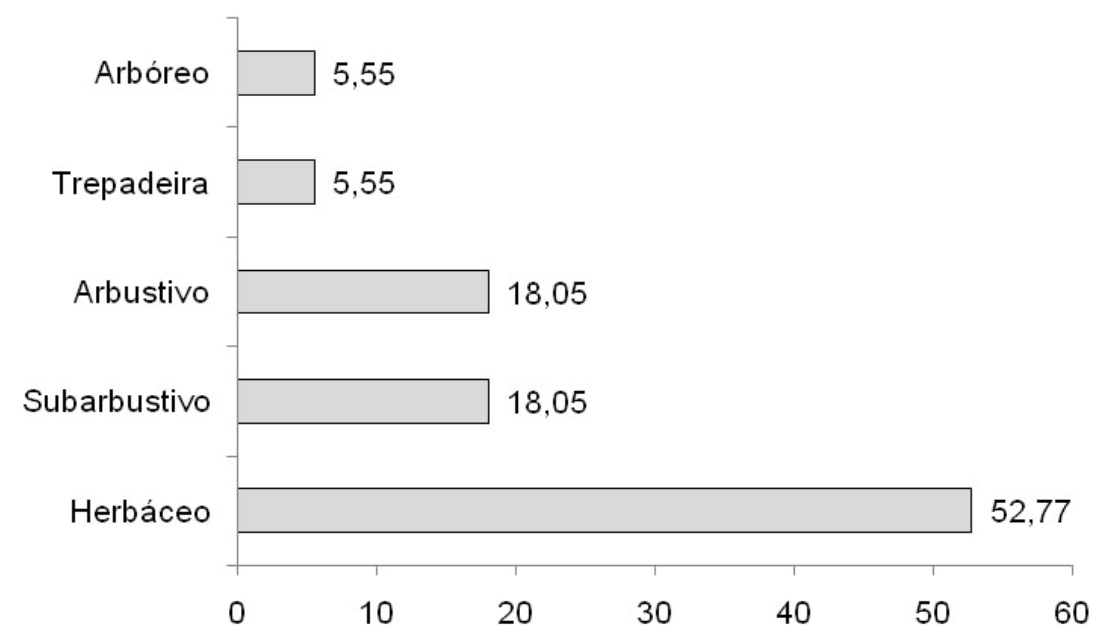

FIGURA 4. Hábito das plantas utilizadas como medicinais (\%) por moradores do bairro Novo Horizonte, Ituiutaba, MG.

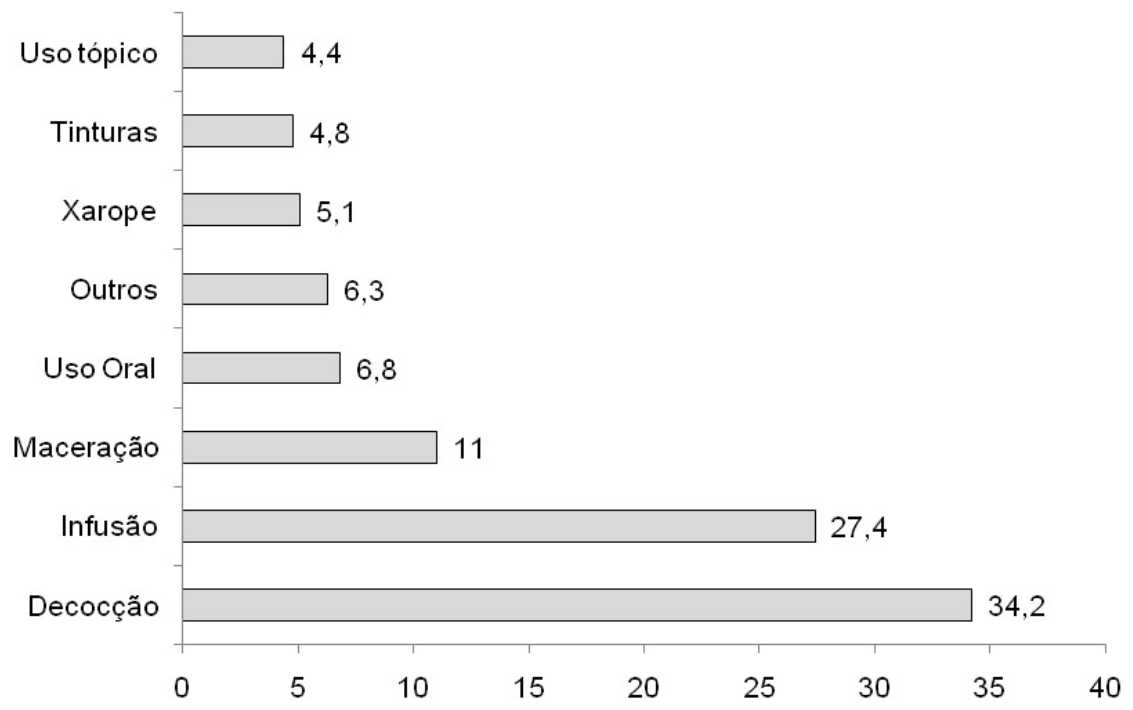

FIGURA 5. Modo de uso e administração dos medicamentos (\%) preparados com plantas pelos moradores do bairro Novo Horizonte, Ituiutaba, MG.

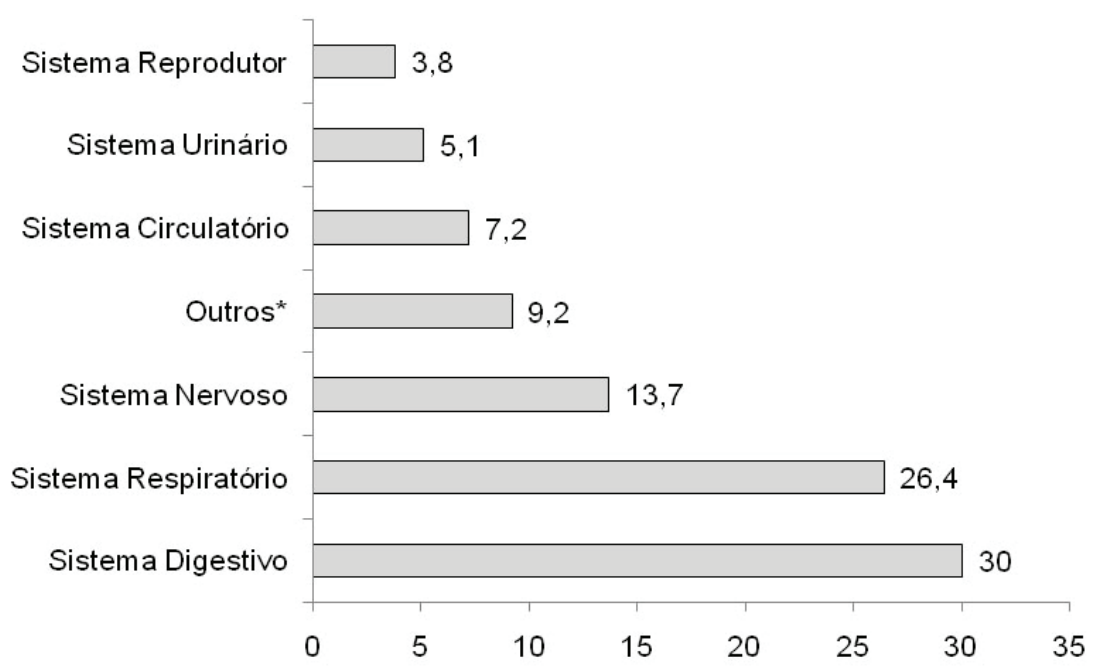

FIGURA 6. Citações por grupo de tratamentos e doenças (\%) por moradores do bairro Novo Horizonte, Ituiutaba, MG. ( ${ }^{*}$ Outros: Machucados, pancadas e arranhões).

Rev. Bras. PI. Med., Campinas, v.15, n.4, p.529-540, 2013. 
necessidades dos moradores.

Em relação à faixa etária, pode-se perceber uma maior quantidade de plantas medicinais nos quintais dos moradores entre 60 e 69 anos, com um total de 106 plantas (Tabela 5).

TABELA 5. Relação entre o número de plantas encontradas nos quintais e a faixa etária dos entrevistados.

\begin{tabular}{cc}
\hline $\begin{array}{c}\text { Idade dos } \\
\text { Entrevistados }\end{array}$ & $\begin{array}{c}\text { Número de plantas } \\
\text { nos quintais }\end{array}$ \\
\hline $20-29$ & 02 \\
$30-39$ & 11 \\
$40-49$ & 30 \\
$50-59$ & 76 \\
$60-69$ & 106 \\
$70-79$ & 38 \\
$80-89$ & 29 \\
\hline Total & $\mathbf{2 9 2}$ \\
\hline
\end{tabular}

\section{DISCUSSÃO}

As mulheres como principais conhecedoras na utilização das plantas medicinais também foram encontradas em estudos recentes, tanto em núcleos urbanos como rurais (Pilla et al., 2006; Pinto et al., 2006; Negrelle et al., 2007; Calábria et al., 2008; Albertasse et al., 2010), não esquecendo-se que o tamanho das amostras para cada gênero e o horário das entrevistas podem ter influenciado nossos resultados. Em outros estudos são os homens que aparecem como a maioria dos entrevistados, possuindo grande conhecimento de plantas (Rodrigues \& Carvalho, 2001; Ming, 2006; Oliveira et al., 2010; Miranda et al., 2011). O conhecimento entre homens e mulheres geralmente pode diferir quando se discute plantas cultivadas e nativas, pois as mulheres, na sua maioria destinadas a cuidar de suas casas, têm um maior contato com quintais, adquirindo um maior conhecimento sobre as plantas cultivadas (Ming, 2006; Miranda et al., 2011). Já o trabalho dos homens geralmente por exigir um contato mais próximo e rotineiro com o campo, possibilita um maior conhecimento das plantas nativas (Ming, 2006). Entretanto, esta observação não é um padrão, pois tanto homens como mulheres podem possuir conhecimento de qualquer tipo de planta, como se observa, por exemplo, no trabalho de Roque et al. (2010), em que as mulheres possuem conhecimento de plantas nativas utilizadas como medicinais. Segundo Gavin \& Anderson (2007), variáveis sócio-econômicas como a profissão, são apontadas como geradores de uma diversificação no uso e na experiência de recursos vegetais entre os indivíduos.

O fator escolaridade não influenciou o conhecimento dos moradores, o que também foi apontado por outros autores, como Pilla et al. (2006) e Albertasse et al. (2010). No presente trabalho, observamos que o conhecimento é transmitido principalmente pelas mães e avós, permitindo assim que este seja repassado e aprendido com o passar do tempo, independente do grau de escolaridade.

Em relação à Lamiaceae e Asteraceae, trabalhos realizados em diversas regiões brasileiras também as apresentam como as famílias mais representativas em número de espécies, como nos estados do Acre (Ming, 2006), Bahia (Pinto et al., 2006), Espírito Santo (Albertasse et al., 2010), Goiás (Silva \& Proença, 2008), Maranhão (Monteles \& Pinheiro, 2007), Minas Gerais (Calábria et al., 2008), Paraná (Negrelle et al., 2007), Rio Grande do Sul (Garlet \& Irgang, 2001; Dorigoni et al., 2001; Vendruscolo \& Mentz, 2006), Rondônia (Santos et al, 2008), Santa Catarina (Giraldi \& Hanazaki, 2010) e São Paulo (Castelluci et al., 2000; Pilla et al., 2006).Vale ressaltar que a maioria das espécies destas famílias apresenta compostos secundários com ação antimicrobiana e antiinflamatória, dentre outras funções (Almassy et al., 2005), com efeitos comprovados por estudos científicos (Lorenzi \& Matos, 2008).

A predominância no hábito herbáceo também pode ser observada em diversos trabalhos (Silva-Almeida \& Amorozo, 1998; Pilla et al., 2006; Pinto et al., 2006; Albertasse et al., 2010).Esta prevalência pode estar associada com o fácil cultivo das ervas em quintais, facilitando a obtenção desses recursos vegetais pelos moradores (Pilla et al., 2006).

A predominância da utilização dos chás como principal modo de preparo no presente estudo também é relatada em outros estudos (Amorozo, 2002; Pilla et al., 2006; Negrelle et al., 2007; Calábria et al., 2008; Albertasse et al., 2010). Mesmo havendo esta similaridade, como relatada para nosso estudo, é importante mencionar que o modo de preparação do medicamento é algo muito diversificado, diferindo de acordo com a região e cultura dos entrevistados conforme observações de Ming (2006) e Roque et al. (2010).

A prevalência das espécies mais encontradas nos quintais está relacionada com a sua utilização, já que estas plantas são usadas na cura das afecções que fazem parte da atenção primária a saúde como: gripe, febre, resfriado, dor de garganta, tosse, dor de cabeça, azia e gastrite (Albertasse et al., 2010). Dentre essas espécies, Mentha sp. 2, Plectranthus barbatus, Cymbopogon citratus e Rosmarinus officinalis também são citadas 
em outros trabalhos (Pilla et al., 2006; Negrelle et al., 2007; Albertasse et al., 2010; Miranda et al., 2011), com efeitos medicinais comprovados cientificamente (Pilla et al., 2006; Lorenzi \& Matos, 2008).

A predominância do uso da folha também foi observada na maioria dos trabalhos etnobotânicos (Pilla et al., 2006; Pinto et al., 2006; Vendruscolo \& Mentz, 2006; Negrelle et al., 2007; Souza, 2007; Albertasse et al., 2010). Sua utilização poderia estar relacionada à facilidade na coleta e à disponibilidade na maior parte do ano (Castellucci et al., 2000), diferentemente de plantas nativas de certas formações vegetacionais, como nas áreas de Caatinga, que não apresentam suas folhas em grande período do ano (Roque et al., 2010).

As doenças do Sistema Digestivo e Respiratório também foram as mais representativas em outros trabalhos (Garlet \& Irgang, 2001; Pilla et al., 2006; Negrelle et al., 2007; Albertasse et al., 2010), provavelmente por pertencerem as afecções mais comuns que atingem os moradores. Estas informações corroboram com os relatos obtidos no PSF do bairro estudado, pois as queixas freqüentes dos moradores são exatamente em relação a afecções relacionadas com o trato respiratório e digestivo (T.W.A. Bueno, comunicação pessoal).

A maior quantidade de plantas medicinais nos quintais das pessoas mais idosas também foi relatada por Miranda et al. (2011). Ainda de acordo com estes autores, quanto maior a idade do entrevistado, mais diverso será o conhecimento em virtude da experiência de vida acumulada.

Percebemos um aumento no cultivo das plantas medicinais conforme a experiência de vida das pessoas, já que houve um acréscimo no número de espécies nos quintais dos entrevistados entre $20 \mathrm{e}$ 69 anos. Já na faixa entre 70 e 89 anos observamos um decréscimo, que poderia ser explicado pela indisposição dos cuidados com o cultivo de plantas destes informantes causados por alguma doença ou pela idade. Apesar da pouca quantidade de plantas nos quintais das pessoas mais idosas, as mesmas têm a tendência de possuir maior conhecimento, 0 que poderia ser explicado por alguns fatores, como a maior oportunidade de aprendizagem e tempo de relação e experimentação dos usos das plantas (Miranda et al., 2011). Importante lembrar que o número de entrevistados por faixa-etária pode ter influenciado para essa interpretação.

Por mais que existam certas particularidades entre os diversos costumes e culturas das comunidades locais no Brasil, observamos uma similaridade com nossos resultados em relação aos demais já realizados na área, reforçando a importância da preservação e divulgação do conhecimento popular.

\section{REFERÊNCIA}

ANVISA (AGÊNCIA NACIONAL DE VIGILÂNCIA SANITÁRIA). Resolução $n^{\circ} \mathbf{1 0}$, de 10 de março de 2010. Dispõe sobre a notificação de drogas vegetais junto à Agência Nacional de Vigilância Sanitária (ANVISA) e dá outras providências. Disponível em: <http://portal.saude.gov.br/portal/arquivos/pdf/ RDC_N_10_drogas_vegetais.pdf >. Acesso em: 07 abril $\overline{2} 0 \overline{11}$.

ALBERTASSE, P.D.; THOMAZ, L.D.; ANDRADE, M.A. Plantas medicinais e seus usos na comunidade da Barra do Jucu, Vila Velha, ES. Revista Brasileira de Plantas Medicinais, v.12, n.3, p.250-60, 2010.

ALBUQUERQUE, U.P. Introdução a Etnobotânica. 2.ed. Rio de Janeiro: Interciência, 2005. 93p.

ALBUQUERQUE, U.P.; ANDRADE, L.H.C. Conhecimento botânico tradicional e conservação em uma área de caatinga no estado de Pernambuco, Nordeste do Brasil. Acta Botanica Brasilica, v.16, n.3, p.273-85, 2002.

ALBUQUERQUE, U.P.A; LUCENA, R.F.P; ALENCAR, N.L. 2010a. Métodos e técnicas para coleta de dados etnobiológicos. In: ALBUQUERQUE, U.P; LUCENA, R.F.P; CUNHA, L.V.F.C. Métodos e técnicas na pesquisa etnobiológica e etnoecológica. Recife, $\mathrm{PE}$ : NUPEA, 2010. p.39-64.

ALMASSY, J.A.A.; LOPES, R.C; ARMOND, C.; SILVA, F.; CASALI, V.W.D. Folhas de Chá: Plantas Medicinais na Terapêutica Humana. Viçosa: Ed. UFV, 2005. 233p.

ALMEIDA, C.F.C.B.R.; AMORIM, E.L.C.; ALBUQUERQUE, U.P.; MAIA, M.B.S. Medicinal plants popularly used in the Xingo region - a semi-arid location in Northeastern Brazil. Journal of Ethnobiology and Ethnomedicine, v.2, n.15, p.1-9, 2006.

AMOROZO, M.C.M. Uso e diversidade de plantas medicinais em Santo Antônio do Leverger, MT, Brasil. Acta Botanica Brasilica, v.16, n.2, p.189-203, 2002.

APG III. An update of the Angiosperm Phylogeny Group classification for the orders and families of flowering plants: APG III. Botanical Journal of the Linnen a Society, v.161, p.105-21, 2009.

AZEVEDO, S.K.S.; SILVA, I.M. Plantas medicinais e de uso religioso comercializadas em mercados e feiras livres no Rio de Janeiro, RJ, Brasil. Acta Botanica Brasilica, v.20,n.1,p.185-94, 2006.

BORGES, M.R. O conhecimento popular sobre plantas como subsídio para uma pesquisa em educação ambiental. 2009. 120p. Dissertação (Mestrado Ecologia e Conservação de Recursos Naturais). Universidade Federal de Uberlândia, Minas Gerais.

BUENO, N. R.; CASTILHO, R. O.; COSTA, R. B.; POTT, A.; POTT, V. J.; SCHEIDT, G. N.; BATISTA, M.S. Medicinal plants used by the Kaiowá and Guarani indigenous populations in the Caarapó Reserve, Mato Grosso do Sul, Brazil. Acta Botanica Brasilica, v.19, n.1, p.3944. 2005.

CALÁBRIA, L.; CUBA, G.T.; HWANG, S.M.; MARRA, J.C.F.; MENDONÇA, M.F.; NASCIMENTO, R.C.; OLIVEIRA, M.R.; PORTO, J.P.M.; SANTOS, D.F.; SILVA, B.L.; SOARES, T.F.; XAVIER, E.M.; DAMASCENO, A.A.; MILANI, J.F.; REZENDE, C.H.A.; BARBOSA, A.A.A.; CANABRAVA, H.A.N. Levantamento etnobotânico e etnofarmacológico de plantas medicinais em

Rev. Bras. PI. Med., Campinas, v.15, n.4, p.529-540, 2013. 
Indianópolis, Minas Gerais, Brasil. Revista Brasileira de Plantas Medicinais, v.10, n.1, p.49-63, 2008.

CASTELLUCCI, S.; LIMA, I.S; NORDI, N.; MARQUES, J.G.W. Plantas medicinais relatadas pela comunidade residente na estação ecológica de Jataí, município de Luís Antônio/SP: uma abordagem etnobotânica. Revista Brasileira de Plantas Medicinais, v.3, n.1, p.51-60, 2000.

DAMASCENO, A.A.; BARBOSA, A.A.A. Levantamento etnobotânico de plantas do bioma Cerrado na comunidade de Martinésia, Uberlândia, MG. Horizonte Científico, v.2, n.1, p.8, 2008.

DI STASI, I.C.; HIRUMA-LIMA, C.A. Plantas medicinais na Amazônia e na Mata Atlântica. 2.ed. São Paulo: Editora UNESP, 2002. 604p.

DORIGONI, P.A.; GHEDINI, P.C.; FRÓES, L.F.; BAPTISTA, K.C.; ETHUR, A.B.M.; BALDISSEROTTO, B.; BÜRGER, M.E.; ALMEIDA, C.E.; LOPES, A.M.V.; ZÁCHIA, R.A. Levantamento de dados sobre plantas medicinais de uso popular no município de São João do Polêsine, RS - Relação entre enfermidades e espécies utilizadas. Revista Brasileira de Plantas Medicinais, v.4, n.1, p.69-79, 2001.

FIDALGO, O.; BONONI, V.L.R. Técnicas de coleta, preservação e herborização de material botânico. São Paulo: Instituto de Botânica, 1989. 62p.

FRANCO, E.A.P.; BARROS, R.F.M. Uso e diversidade de plantas medicinais no Quilombo Olho D'água dos Pires, Esperantina, Piauí. Revista Brasileira de Plantas Medicinais, v.8, n.3, p.78-88, 2006.

GARLET, T.M.B.; IRGANG, B.E. Plantas medicinais utilizadas na medicina popular por mulheres trabalhadoras rurais de Cruz Alta, Rio Grande do Sul, Brasil. Revista Brasileira de Plantas Medicinais, v.4, n.1, p.9-18, 2001.

GAVIN, M.C.; ANDERSON, G.J. Socioeconomic predictors of forest use values in the Peruvian Amazon: a potential tool for biodiversity conservation. Ecological Economics, v.60, p. 752-62, 2007.

GIRALDI, M.; HANAZAKI, N. Uso e conhecimento tradicional de plantas medicinais no Sertão do Ribeirão, Florianópolis, SC, Brasil. Acta Botanica Brasilica, v.24, n.2, p.395-406, 2010.

IBGE. Censo demográfico 2010. Sinopse preliminar. Disponível em: <http://www.ibge.gov.br/cidadesat/ topwindow.htm?1>. Acesso em: 05 maio 2011.

LIPORACCI, H.S.N.; SIMÃO, D.G.; CORREIA; I.T. Conhecimento popular das plantas no universo rural. In: KATRIB, C.M.I.; MACHADO, M.C.T.; ABDALA, M.C. (Org.). São Marcos do Sertão Goiano, Cidades, Memória e Cultura. Uberlândia: EDUFU, 2010. p.261270.

LORENZI, H.; MATOS, F.J.A.M. Plantas Medicinais no Brasil: nativas e exóticas. 2.ed. Nova Odessa: Instituto Plantarum, 2008. 544p.

LORENZI, H.; SOUZA, V.C. Botânica Sistemática: Guia ilustrado para identificação das famílias de Angiospermas da flora brasileira, baseado em APG II. 2.ed. Nova Odessa: Instituto Plantarum, 2008. 704p. LORENZI, H.; SARTORI, S.F.; BACHER, L.B.; LACERDA, M.T.C. Frutas Brasileiras e Exóticas Cultivadas: de consumo in natura. 1.ed. Nova Odessa: Instituto Plantarum, 2006. 650p.
MARODIN, S.M; BAPTISTA, L.R.M. O uso de plantas com fins medicinais no município de Dom Pedro de Alcântara, Rio Grande do Sul, Brasil. Revista Brasileira de Plantas Medicinais, v.4, n.1, p.57-68, 2001.

MILANI, J.F.; GUIDO, L.F.E; BARBOSA, A.A.A. Educação Ambiental a partir do resgate dos quintais e seu valor etnobotânico no distrito Cruzeiro dos Peixotos, Uberlândia, MG. Horizonte Científico, v.5, n.1, p.132, 2011.

MING, L.C.AEtnobotânica na recuperação do conhecimento popular. In: ENCONTRO INTERNACIONAL SOBRE AGROECOLOGIA E DESENVOLVIMENTO RURAL SUSTENTÁVEL, 2001, Botucatu. Anais do Encontro Internacional sobre Agroecologia e Desenvolvimento Rural Sustentável. Botucatu: UNESP, 2001. p. 3.

MING, L.C. Plantas medicinais na reserva extrativista Chico Mendes (Acre): uma visão etnobotânica. São Paulo: Editora UNESP, 2006. 160p.

MIRANDA, T.M.; HANAZAKI, N.; GOVONE, J.S.; ALVES, D.M.M. Existe utilização efetiva dos recursos vegetais conhecidos em comunidades caiçaras da Ilha do Cardoso, estado de São Paulo, Brasil? Rodriguésia, v.62, n.1, p.153-169, 2011.

MONTELES, R.; PINHEIRO, C.U.B. Plantas medicinais em um quilombo maranhense: uma perspectiva etnobotânica. Revista de Biologia e Ciências da Terra, v.7, n.2, p.38-48, 2007.

NEGRELLE, R.R.B.; TOMAZZONI, M.I; CECCON, M.F; VALENTE, T.P. Estudo etnobotânico junto à Unidade Saúde da Família Nossa Senhora dos Navegantes: subsídios para o estabelecimento de programa de fitoterápicos na Rede Básica de Saúde do município de Cascavel (Paraná). Revista Brasileira de Plantas Medicinais, v.9, n.3, p.6-22, 2007.

OLIVEIRA, F.C.S.; BARROS, R.F.M.; MOITANETO, J.M. Plantas medicinais utilizadas em comunidades rurais de Oeiras, semiárido piauiense. Revista Brasileira de Plantas Medicinais, v.12, n.3, p.282-301, 2010.

PASA, M.C.; ÁVILA, G. Ribeirinhos e recursos vegetais: a etnobotânica em Rondonópolis, Mato Grosso, Brasil. Interações, v.11, n.2, p.195-204, 2010.

PILLA, M.A.C.; AMOROZO, M.C.M.; FURLAN, A. Obtenção e uso das plantas medicinais no distrito de Martim Francisco, Município de Mogi-Mirim, SP, Brasil. Acta Botanica Brasilica, v.20, n.4, p.789-802, 2006.

PINTO, E.P.P.; AMOROZO, M.C.M.; FURLAN, A. Conhecimento popular sobre plantas medicinais em comunidades rurais de mata atlântica - Itacaré, BA, Brasil. Acta Botanica Brasilica, v.20, n.4, p.751-62, 2006.

PREFEITURA MUNICIPAL DE ITUIUTABA. Município. Disponível em: <http://www.ituiutaba.mg.gov.br>. Acesso em: 05 maio 2011.

RODRIGUES, V.E.G.; CARVALHO, D.A. Levantamento etnobotânico de plantas medicinais no domínio do cerrado na região do Alto Rio Grande, Minas Gerais. Ciência Agrotécnica, v.25, n.1, p.102-23, 2001.

ROQUE, A.A.; ROCHA, R.M; LOIOLA, M.I.B. Uso e diversidade de plantas medicinais da Caatinga na comunidade rural de Laginhas, município de Caicó, Rio Grande do Norte (nordeste do Brasil). Revista Brasileira de Plantas Medicinais, v.12, n.1, p.31-42, 2010.

Rev. Bras. PI. Med., Campinas, v.15, n.4, p.529-540, 2013. 
SALGADO, C.L.; GUIDO, L.F.E. O conhecimento popular sobre plantas: um estudo etnobotânico em quintais do distrito de Martinésia, MG. In: IV ENCONTRO DA ASSOCIAÇÃO NACIONAL DE PESQUISA E PÓSGRADUAÇÃO EM AMBIENTE E SOCIEDADE, 2008, Brasília. Anais do IV Encontro da Associação Nacional de Pesquisa e Pós-Graduação em Ambiente e Sociedade, Brasília, 2008.

SANTOS, L.L; VIEIRA, F.J; NASCIMENTO, L.G.S.N; SILVA, A.C.O; SOUZA, G.M. 2010b. Técnicas para coleta e processamento de material botânico e suas aplicações na pesquisa etnobotânica. In: ALBUQUERQUE, U.P; LUCENA, R.F.P; CUNHA, L.V.F.C. Métodos e técnicas na pesquisa etnobiológica e etnoecológica. Recife, PE: NUPEA, 2010. p.279-295.

SANTOS, J.F.L.; AMOROZO, M.C.M.; MING, L.C. Uso popular de plantas medicinais na comunidade rural da Vargem Grande, Município de Natividade da Serra, SP. Revista Brasileira de Plantas Medicinais, v.10,n.3, p.67-81, 2008.

SILVA-ALMEIDA, M.F.; AMOROZO, M.C.M. Medicina popular no Distrito de Ferraz, Município de Rio Claro, SP. Brazilian Journal of Ecology, v.2, n.1, p. 36-46, 1998.

SILVA, A.J.R.; ANDRADE, L.H.C. Etnobotânica nordestina: estudo comparativo da relação entre comunidades e vegetação na Zona do Litoral - Mata do Estado de Pernambuco, Brasil. Acta Botanica Brasilica, v.19, n.1, p.45-60,2005.
SILVA, E.J.E.; LOECK, A.E. Ocorrência de formigas domiciliares (Hymenoptera: Formicidae) em Pelotas, RS. Revista Brasileira de Agrociência, v.5, n.3, p.220-24, 1999.

SILVA, C.S.P.; PROENÇA, C.E.B. Uso e disponibilidade de recursos medicinais no município de Ouro Verde de Goiás, GO, Brasil. Acta Botanica Brasilica, v.22, n.2, p.481-92, 2008.

SIMÃO, C.G. Áreas cultivadas na Comunidade Cachoeira do Guilherme, na Estação Juréia-Itatins, SP. 2003. 133p. Dissertação (Mestrado - Ecologia de Agroecossistemas) - ESALQ/USP, Piracicaba, São Paulo.

SOUZA, L.F. Recursos vegetais usados na medicina tradicional do Cerrado (comunidade de Baús, Acorizal, MT, Brasil). Revista Brasileira de Plantas Medicinais, v.9, n.4, p.44-54, 2007.

TROPICOS. Tropicos.org. Missouri Botanical Garden. Disponível em <http://www.tropicos.org>. Acesso em: 30 jul. 2012.

USTULIN, M.; FIGUEIREDO, B.B.; TREMEA, C.; POTT, A.; POTT, V.J.; BUENO, N.R.; CASTILHO, R.O. Plantas medicinais comercializadas no Mercado Municipal de Campo Grande-MS. Revista Brasileira de Farmacognosia, v.19, n.3, p. 805-813,2009.

VENDRUSCOLO, G.S.; MENTZ, L.A. Levantamento etnobotânico das plantas utilizadas como medicinais por moradores do bairro Ponta Grossa, PortoAlegre, Rio Grande do Sul, Brasil. IHERINGIA, Série Botânica, v.61, n.1-2, p. 83-103, 2006. 